\title{
Identification and Host Relations of Turnip ringspot virus, A Novel Comovirus from Ohio
}

\author{
P. Rajakaruna and S. Khandekar, Department of Biological Sciences, University of Toledo, Toledo, OH 43606; \\ T. Meulia, Molecular and Cellular Imaging Center, The Ohio Agricultural Research and Development Center, Woos- \\ ter, OH 44691; and S. M. Leisner, Department of Biological Sciences, University of Toledo, Toledo, OH 43606
}

\begin{abstract}
Rajakaruna, P., Khandekar, S., Meulia, T., and Leisner, S. M. 2007. Identification and host relations of Turnip ringspot virus, a novel comovirus from Ohio. Plant Dis. 91:1212-1220.

Viruslike chlorotic ring spot symptoms and line patterns of unknown origin were observed on a greenhouse-grown turnip plant. The suspected virus was mechanically transmissible to plants in the Brassicaceae. Electron microscopic analysis revealed icosahedral particles approximately 28 $\mathrm{nm}$ in diameter. Reverse transcriptase-polymerase chain reaction (RT-PCR) analyses suggested that the pathogen is a comovirus, an observation that was confirmed by analysis of portions of the genomic sequence. This virus was provisionally named Turnip ringspot virus (TuRSV). Based on the RNA 1 sequence, TuRSV is most similar to Radish mosaic virus, another pathogen that infects members of the Brassicaceae. Arabidopsis thaliana is susceptible to TuRSV, and 12 out of the 23 ecotypes studied showed symptoms when inoculated with the virus. TuRSV induced a variety of responses on ecotypes from death to no infection. Some ecotypes showed one or two rounds of symptom display followed by recovery when inoculated with TuRSV. About half of the ecotypes (11/23) analyzed showed no symptoms when inoculated with TuRSV. Col-0 plants showed no symptoms, and infectious virus was not recovered from systemic leaves, although it could be detected by RT-PCR. Col-0 plants harboring mutations impairing the ethylene, jasmonic acid, or salicylic acid signaling pathways did not show symptoms when inoculated with TuRSV.
\end{abstract}

Additional keyword: Comoviridae

Comoviruses are positive-sense, singlestranded, RNA viruses that infect a variety of plant species $(14,17)$. These viruses possess bipartite genomes encoding two polyproteins, one on each RNA. The polyproteins are post-translationally processed by a virus-encoded protease to yield the mature forms of each polypeptide. Although comoviruses infect a variety of plant species, relatively few have been reported to cause disease in members of the Brassica family $(5,6,9,10,29)$.

Some comoviruses possess intriguing virus-host relations. For example, Bean pod mottle virus exhibits two flushes of symptom induction and recovery when inoculated to soybean (13). However, the mechanism(s) behind this unusual progression of symptoms is unclear. In many cases where recovery from viral infections is

Corresponding author: S. M. Leisner

E-mail: sleisne@utnet.utoledo.edu

Accession numbers: DQ665367 and EF191015.

Accepted for publication 17 April 2007.

doi:10.1094/PDIS-91-10-1212

(C) 2007 The American Phytopathological Society observed, post-transcriptional gene silencing/RNA interference (RNAi) is involved $(34,35)$. This process permits specific degradation of viral RNA. In addition, plants possess other pathways for protection against viral infection. For example, pathways utilizing salicylic acid, ethylene, or jasmonic acid as signaling molecules protect plants against pathogens $(12,36)$. Plants with defects in these signaling pathways are impaired in their ability to resist infection.

In the work described here, a novel Brassica-infecting comovirus is characterized, the host relations of this virus are examined, and the response shown by a particular ecotype of Arabidopsis thaliana (Col-0) to this virus is investigated.

\section{MATERIALS AND METHODS}

Plant materials. Turnips (Brassica rapa cv. Just Right) were inoculated with cell sap from infected turnip plants (21). Sap was prepared by harvesting turnip leaves infected by the virus that was later provisionally named Turnip ringspot virus (TuRSV). The leaves were subsequently homogenized in $3 \mathrm{ml}$ of grinding buffer (GB; $10 \mathrm{mM}$ potassium acetate, $\mathrm{pH}$ 7.2) per gram of tissue. Celite (diatomaceous earth) was added, and the suspension was mixed and rub-inoculated onto leaves 6,7 , and 8 of turnips at the 12-leaf stage. Inoculated plants were grown in a greenhouse at $22^{\circ} \mathrm{C}$ under natural lighting. Inoculated plants were observed for symptoms until about 30 days postinoculation (DPI). Because more consistent inoculation results were obtained with TuRSV from $A$. thaliana, the virus was maintained in the Aa- 0 ecotype by serial passage.

The A. thaliana ecotypes used in this study were provided by S. H. Howell (Iowa State University, Ames). In this study, the pad4 and nprl Col-0 mutants in the salicylic acid-signaling pathway $(8,37)$ were used. The ein 2 and etrl mutants in the ethylene-signaling pathway (15) were studied. Finally, the jarl mutant that is impaired in the jasmonic acid-signaling pathway (30) was examined. All mutants were kindly provided by The Arabidopsis Biological Resource Center at the Ohio State University (Columbus).

A. thaliana seeds were planted in moistened Redi Earth potting soil (BFG Supply, Burton, OH). Plants were propagated in a growth chamber under continuous light of $60 \mu \mathrm{E} \cdot \mathrm{m}^{-2} \cdot \mathrm{s}^{-1}$ photosynthetic active radiation (PAR) at $20^{\circ} \mathrm{C}$ and fertilized with mineral nutrient solution as described previously (1). A. thaliana were inoculated with sap from Aa- 0 plants prepared by grinding symptomatic leaves in $3 \mathrm{ml}$ of GB per gram of tissue. Celite was added, and the suspension was mixed and rub-inoculated onto rosette leaves 6 , 7,8 , and 9 of $A$. thaliana plants at the $10-$ leaf stage with a plastic spatula (1). Following inoculation, A. thaliana plants were propagated in a growth chamber under a 12-h light (at $60 \mu \mathrm{E} \cdot \mathrm{m}^{-2} \cdot \mathrm{s}^{-1}, \mathrm{PAR}$ ), 12-h dark regime at $20^{\circ} \mathrm{C}$ and fertilized with mineral nutrient solution as described previously. Plants were observed daily for symptom production up to 84 DPI. Each experiment employed 15 to 20 plants of each ecotype and was performed at least three times. To examine Col-0 infection, sap was prepared from wildtype and mutant Col-0 plants inoculated with TuRSV, harvested at 14 DPI, and inoculated to Aa-0 plants as described above. 
Partial virus purification. TuRSV was partially purified by a combination of differential and sucrose density gradient centrifugation. Symptomatic A. thaliana Aa-0 leaves were harvested at approximately 10 DPI. Leaf tissue was ground with a mortar and pestle at $4^{\circ} \mathrm{C}$ in 3 to $4 \mathrm{ml}$ of GB per gram of tissue, filtered through three layers of cheesecloth, and the filtrate transferred to $50-\mathrm{ml}$ centrifuge tubes. The filtrate was centrifuged at $11,950 \times g$ for $15 \mathrm{~min}$ at $4^{\circ} \mathrm{C}$. The supernatant was filtered through one layer of Miracloth (Calbiochem, La Jolla, CA) and then centrifuged for $1 \mathrm{~h}$ at $145,921 \times g$ at $4^{\circ} \mathrm{C}$. The pellets were resuspended in GB, layered onto $50 \mathrm{ml}$ of 10 to $40 \%$ sucrose gradients, and centrifuged in an SW28 rotor for $2 \mathrm{~h}$ at $96,467 \times g$ at $4^{\circ} \mathrm{C}$. The gradients were fractionated in 5 $\mathrm{ml}$ aliquots. Portions of each fraction were diluted 100-fold with sterile distilled water, Celite was added, and the diluted fractions were inoculated to Aa-0 plants. Aa-0 plants inoculated with samples collected near the center-upper portion of the gradient showed symptoms within 5 days and the plants often died. Aa-0 plants inoculated with the other gradient fractions took at least 2 weeks, if at all, to show symptoms. This purification was performed three times with similar results.

Those fractions with the highest infectivity were diluted 10-fold with GB, transferred to 50-ml ultracentrifuge tubes, and centrifuged at $209,406 \times g$ at $4^{\circ} \mathrm{C}$ for $2 \mathrm{~h}$. The pellets were pooled and resuspended in $0.5 \%$ of the total initial volume of $4{ }^{\circ} \mathrm{C}$ GB. The resuspended pellets were termed virus concentrate. Virus concentrate was subjected to electron microscopy as described previously (27).

Reverse transcriptase-polymerase chain reaction (RT-PCR) amplification, cloning, and sequence analysis of TuRSV genomic fragments. One gram of symptomatic systemically infected Aa-0 rosette leaf tissue was harvested at 14 DPI and sent to Agdia (Elkhart, IN) for RTPCR analysis. RT-PCR was conducted with proprietary pan-comovirus primers, and the PCR product, approximately 450 bp, was kindly sent back to the authors.

This PCR product was purified by electrophoresis through a $0.8 \%$ agarose gel made with TAE (1 mM EDTA, $40 \mathrm{mM}$ Tris-acetate, $\mathrm{pH} 8.3$ ) buffer. The $\sim 450$-bp band was excised and the DNA fragment purified using the Amicon Ultrafree-DA DNA extraction spun column system (Millipore, Bedford, MA). The extracted PCR product was phenol extracted and concentrated by ethanol precipitation (3). The PCR product was then inserted into the pCR2.1 vector by ligation using the TA Cloning Kit by Invitrogen Corporation (Carlsbad, CA) according to the manufacturer's specifications. The ligation mixture was introduced into Escherichia coli strain DH5 $\alpha$ by calcium chloride transformation. E. coli harboring the pCR2.1 plasmids with the PCR product were identified by digestion with EcoRI. Those pCR2.1 plasmids with inserts were then sent to MWG Biotech (High Point, NC) for sequencing using the M13 universal forward and reverse primers. Three clones were sequenced in both directions and all were identical. This sequence was examined using BLAST (Basic Local Alignment Search Tool) (2). A preliminary alignment was performed on the comoviral sequences to identify conserved regions downstream of those aligning with the TuRSV sequence. From this, the degenerate reverse oligonucleotide TuRSV-2RC (5' GTIGGCAAACCTCCCCTTCC $3^{\prime}$ ) was designed. A forward oligonucleotide, TuRSV-1F (5' ACTCCTTTTGTGGAGGAGAC $3^{\prime}$ ), was designed from inside the above PCR fragment.

Preliminary multiple sequence alignment was performed on RNA 2 of the comoviral genomes in GenBank, and this information was used to design two PCR primers: TuRSV2-1F, 5' CATTTAATCCAAACCCTTGT $3^{\prime}$, and TuRSV2-2R, 5' ACCAGCACCICCACCTATAG 3'. These primers were predicted to amplify a fragment of approximately 900 bp when used in RT-PCR.

Approximately $0.3 \mathrm{~g}$ of TuRSV-infected turnip tissue was harvested at 21 DPI, frozen in liquid nitrogen, and ground in a mortar and pestle. Total RNA was isolated from the infected plant tissue using TRIZOL Reagent (http://plantpath.wisc.edu/ $\sim$ amyc/Protocols/protocols\%20-\%20plant\% 20viruses.htm). Approximately $5 \%$ of the RNA isolated was mixed with $1 \mu \mathrm{g}$ of random hexamer oligonucleotides, heated at $70^{\circ} \mathrm{C}$ for $10 \mathrm{~min}$, and then plunged into ice for $5 \mathrm{~min}$. Reverse transcriptase reactions were then initiated in a total volume of 20 $\mu \mathrm{l}$ by the addition of $100 \mathrm{U}$ of MMLV reverse transcriptase (Promega Corporation, Madison, WI), $20 \mathrm{U}$ of Optizyme Recombinant RNase Inhibitor (Promega), and all four deoxynucleotide triphosphates in the buffer provided by Promega according to their specifications. Samples were incubated at $42^{\circ} \mathrm{C}$ for $1 \mathrm{~h}$. Following incubation, $1 \mu \mathrm{l}$ of the reverse transcriptase mixture was used for PCR.

All PCR reaction mixtures contained a final concentration of $50 \mathrm{mM} \mathrm{KCl}, 1.5$ $\mathrm{mM} \mathrm{MgCl}_{2}, 10 \mathrm{mM}$ Tris- $\mathrm{HCl}$ (pH 9.0), $0.1 \%$ Triton $\mathrm{X}-100,200 \mu \mathrm{M}$ each dNTP, $0.5 \mathrm{U}$ Taq DNA polymerase (Promega), as well $200 \mathrm{~nm}$ each TuRSV-1F and TuRSV2RC primers (Integrated DNA Technologies, Inc., Coralville, IA) (for RNA 1) or the TuRSV2-1F and TuRSV2-2R primers (for RNA 2). The PCR program consisted of a 35 cycle amplification program of 1 $\min$ at $92^{\circ} \mathrm{C}, 1 \mathrm{~min}$ at $45^{\circ} \mathrm{C}$, and $1 \mathrm{~min}$ at $72^{\circ} \mathrm{C}$. The amplifications were performed in 500- $\mu$ l thin wall microcentrifuge tubes in an Eppendorf Mastercycler Personal (Brinkman Instruments, Inc., Westbury, NY). PCR products were separated by electrophoresis through a $2 \%$ agarose gel in TBE buffer (3). A TuRSV RNA 1 fragment of approximately $900 \mathrm{bp}$ and a fragment about 800 bp from RNA 2 were amplified by this approach. The sequence for the TuRSV RNA 1 fragment (accession no. DQ665367) and the portion of RNA 2 aligning with other plant viruses (accession no. EF191015) were submitted to GenBank.

To monitor both viral RNAs simultaneously, two new sets of primers were designed. One pair, TuRSV RNA1sp-1F: 5' TCGCAGGCTAGAAGATTGTGA $3^{\prime}$ and TuRSV RNA1sp-2R: 5' GGCCCTAAG TGTTCCTGGTC 3', was used to amplify a 369-bp fragment from TuRSV RNA 1 (nucleotides 705-1073). A second pair, TuRSV RNA2sp-1F: 5' CTGAGCGCC TAAGTGATGTTCT $3^{\prime}$ and TuRSV RNA2sp-2R: 5' CTTTACCTCGGATAC CACTGTTGT 3', was used to amplify a 168-bp fragment from TuRSV RNA 2 (nucleotides 23-190). PCR reactions were performed as above but with both sets of primers in the same reaction mixture. To test the specificity of these primers, approximately $0.05 \mathrm{~g}$ of dried Radish mosaic virus (RaMV)-infected tissue (ATCC number PV-138) was ground in an RNase free $1.5-\mathrm{ml}$ tube on dry ice. RNA was then isolated from the tissue using the Purelink Plant RNA Reagent (Invitrogen) according to the manufacturer's specifications. RTPCR was carried out as described above.

The sequence of the putative protein segment encoded by the TuRSV PCR products was compared with the deduced translation product encoded by the aligned segment of either RNA 1 or RNA 2 of other plant viruses by performing a BLAST search (2) for related sequences. Alignments with plant viral sequences with BLAST scores greater than 80 when compared with the TuRSV sequences were performed using the ClustalW program contained within the MegAlign program of the DNASTAR Lasergene 7 software package (Madison, WI) using a Gonnet matrix. The pairwise alignment parameters included a gap penalty of 10.0 and a gap length of 0.1 . Multiple alignment parameters were set at a gap penalty of 10.0, a gap length penalty of 0.2 , and delay divergent sequences of $30 \%$. The phylogenetic relationship between these viruses was calculated from the distance data. Unrooted phylogenetic trees were constructed using maximum parsimony, and branching patterns were tested by bootstrap analysis of 1,000 trials by employing the PAUP program (31).

Polyacrylamide gel electrophoretic analysis of TuRSV-infected plants. Partially purified virus preparations from the various sucrose gradient fractions were mixed with one-third volume of sample buffer (6\% sodium dodecyl sulfate [SDS], $35 \%$ glycerol, $15 \%$ 2-mercaptoethanol, $0.1 \%$ bromophenol blue, $188 \mathrm{mM}$ Tris- 
$\mathrm{HCl}, \mathrm{pH} 6.8$ ), and they were incubated for $5 \mathrm{~min}$ at $95^{\circ} \mathrm{C}$. The heated samples were permitted to cool and subsequently loaded onto a 10\% SDS-polyacrylamide gel (Mini-Protean3; BioRad, Hercules, CA) with a $4 \%$ stacking gel (3). Gels were run for $1 \mathrm{~h}$ at $16 \mathrm{~V} / \mathrm{cm}$ (95 volts). Polyacrylamide gels were stained overnight in $30 \%$ methanol, $10 \%$ acetic acid, $0.025 \%$ Coomassie Brilliant Blue R250. Gels were destained at room temperature two times for $20 \mathrm{~min}$ in $40 \%$ methanol, $7 \%$ acetic acid. Gels were then destained two additional times for 30 min each in 5\% methanol, $7 \%$ acetic acid.

Protein bands were excised from the gel by laser and sequenced by the Michigan Proteome Consortium (Ann Arbor, MI). Briefly, the samples were digested with trypsin. The resulting peptides were extracted from the gel plugs with $2 \%$ acetonitrile, $0.1 \%$ TFA. The extracted peptides were spotted onto the wells of a Maldi target and overlaid with matrix. The analyses were performed using the ABI 4800 Maldi TOF/TOF.

\section{RESULTS}

Identification of a virus causing ring spot symptoms on turnips in Ohio. In the spring of 1996, a turnip was discovered in a greenhouse on the University of Toledo campus that showed chlorotic ring spot symptoms and line patterns along the major veins on leaves. Leaf samples were harvested, dried over anhydrous calcium chloride, and stored for 6 years at $4^{\circ} \mathrm{C}$. In 2002, the leaf tissue was removed from storage and inoculated to turnips. The infectious agent induced systemic symptoms on turnips by 8 DPI. Hence, the infectious agent survived in dried leaf tissue for 6 years and was mechanically transmissible. This infectious agent typically did not induce symptoms on the inoculated turnip leaves. The initial symptoms appeared as chlorotic lesions on systemic leaves. By about 25 DPI, older systemic leaves showed chlorotic ring spots and line patterns along veins, while the younger leaves exhibited mainly chlorotic lesions (Fig. 1). In some cases, the line patterns were extensive and outlined leaf regions. Beyond the chlorotic symptoms caused by the virus on noninoculated leaves, infection had few other effects on plant growth. Occasionally, mild stunting was observed on infected turnips. The symptoms appeared to be seasonal, being more prominent in the winter months than during the summer. This pathogen was provisionally termed Turnip ringspot virus (TuRSV).
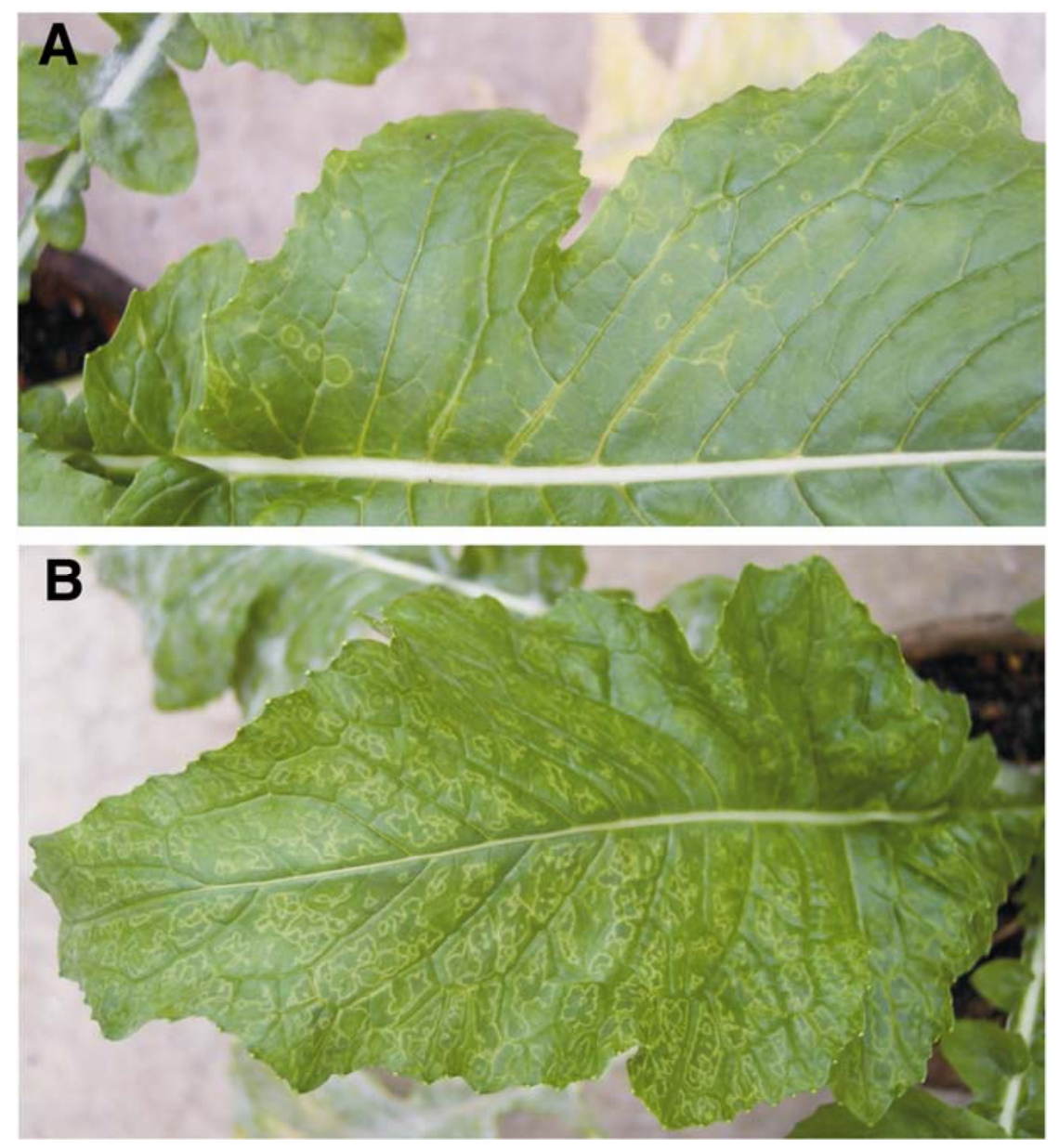

Fig. 1. Turnip ringspot virus (TuRSV) symptoms on turnip leaves. Turnip leaves systemically infected with TuRSV were photographed at 25 days postinoculation. A, Older systemically infected leaf showing ringspots. B, Younger systemically infected leaf showing extensive ringspot-line pattern symptoms.
TuRSV is a comovirus. Initial leaf dip electron microscopic analysis of TuRSVinfected plant tissue proved inconclusive, suggesting that the virus was not present at high titers. Therefore, partially purified virus fractions were prepared (see Materials and Methods) and analyzed by negative stain electron microscopy. The virus particles were icosahedral in shape and approximately $28 \mathrm{~nm}$ in diameter (Fig. 2A).

RT-PCR assays performed by Agdia using pan-comovirus primers indicated that TuRSV was a comovirus. The RT-PCR product was cloned and sequenced. The PCR product was 429 bp in length (Fig. 3), and it encoded a contiguous open reading frame of 143 amino acids. Based on multiple sequence alignment, the putative polypeptide encoded by the TuRSV RT-PCR product aligned with amino acids 13541496 of Cowpea mosaic virus (CPMV; accession no. NP_613203) RNA 1 polyprotein (23). CPMV was used for a comparison because it is the type member of the genus Comovirus and the complete sequence is known.

To obtain additional nucleotide sequence information from TuRSV, the RNA 1 polyprotein coding sequences for the other comoviruses were aligned, and a conserved region downstream of that aligning with the TuRSV sequences was identified. A degenerate primer based on this conserved region was designed and a larger portion of the TuRSV sequence was amplified by RT-PCR. In toto, the TuRSV RNA 1 sequence reported here is 1,188 nucleotides long and encodes a putative continuous polypeptide of 396 amino acids (Fig. 3) that aligns with CPMV RNA 1 polyprotein amino acids 1354-1750. This region is contained within the portion of the comoviral polyprotein corresponding to the $87-\mathrm{kDa}$ replicase (23). Multiple sequence alignment of the 1,188-bp segment confirms that TuRSV is most similar to the comoviruses. The TuRSV RT-PCR product was most similar to RaMV (accession no. AAY32935) (26). The TuRSV RNA 1 RT-PCR product was $70.1 \%$ identical to RaMV at the nucleotide and $78.7 \%$ at the amino acid sequence level. Identity to the other comoviruses is between 55 and $65 \%$ at the amino acid and 55 and $60 \%$ at the nucleotide sequence level. The unrooted phylogenetic tree constructed from the polypeptide multiple sequence alignment data indicated that the comoviruses cluster together and TuRSV was a part of this clade (Fig. 4). However, TuRSV and RaMV formed their own subcluster within that of the genus Comovirus.

To obtain sequence information on the other TuRSV genomic segment, RNA 2 sequences for six comoviruses were aligned and two primers were designed to the conserved region spanned by nucleotides 1914-2899 in CPMV (accession no. NC_003550). These primers were used to amplify a 742-bp fragment of RNA 2 from 
TuRSV-infected turnip leaves. However, when the sequence of six independent clones (all of which were identical) was translated in silico, only a 420-bp portion of this PCR product that encoded 140 amino acids (Fig. 5) aligned with other comovirus RNA 2 sequences. This 140 amino acid segment aligned with amino acids 496-635 of the CPMV RNA 2encoded polyprotein (GenBank accession no. CAA25314). Multiple sequence alignment showed that the TuRSV RNA 2 sequence identity with other comovirus proteins varied from 35.3 to $47.1 \%$ and 47.1 to $51.6 \%$ at the RNA level. The unrooted phylogenetic tree derived from the distance data of the polypeptide sequences indicated that TuRSV is distinct from the other comoviruses.

RT-PCR detection of TuRSV. Since sequence data were now available for portions of each TuRSV genomic segment, this information was used to design primers to simultaneously detect both viral RNAs in infected plants by RT-PCR. These primers were also used to test Koch's postulates (17).

RT-PCR products corresponding to both viral RNAs were detected in TuRSVinoculated leaves of Aa- 0 plants, as well as in noninoculated rosette and cauline leaves (Fig. 2B). However, no PCR products were detected in noninoculated Aa-0 control plants. RT-PCR products corresponding to both TuRSV RNAs were detected in partially purified virus preparations. The two TuRSV RT-PCR products were also detected in the leaves of Aa- 0 plants inoculated with the partially purified virus preparations, as well as in noninoculated rosette and cauline leaves. This, in addition to the observation that the plants inoculated with the partially purified virus showed symptoms identical to those inoculated with the original virus, fulfilled Koch's postulates.

To determine specificity, the two primer sets were used to attempt to amplify fragments from RaMV, the virus most closely related to TuRSV based on the RNA 1 sequence. Interestingly, only the RT-PCR product corresponding to RNA 2 was amplified with this primer set. The RT-PCR product corresponding to RNA 1 was not detected in these preparations. Hence, the RNA 1 primer pair is specific for TuRSV and further confirmed that this virus is distinct from RaMV.

Analysis of putative TuRSV capsid proteins. To detect possible TuRSV capsid proteins in plant tissue samples, sodium dodecyl sulfate-polyacrylamide gel electrophoresis (SDS-PAGE) was performed, followed by Coomassie blue staining. This analysis detected several protein bands that were more prominent in TuRSV-infected than in noninoculated turnips. However, sequence analysis indicated that none of these bands contained viral polypeptides (data not shown). Therefore, TuRSV was partially purified as above and the viruscontaining fractions were pooled, concentrated, and subjected to SDS-PAGE. Three bands were visible in the 55 to $24 \mathrm{kDa}$ range and a prominent band at approximately $17 \mathrm{kDa}$ was observed (data not shown). All four bands were excised and examined by mass spectrometry/mass spectrometry analysis. The largest and smallest bands and a band approximately $35 \mathrm{kDa}$ in size were identified as ribo-

A

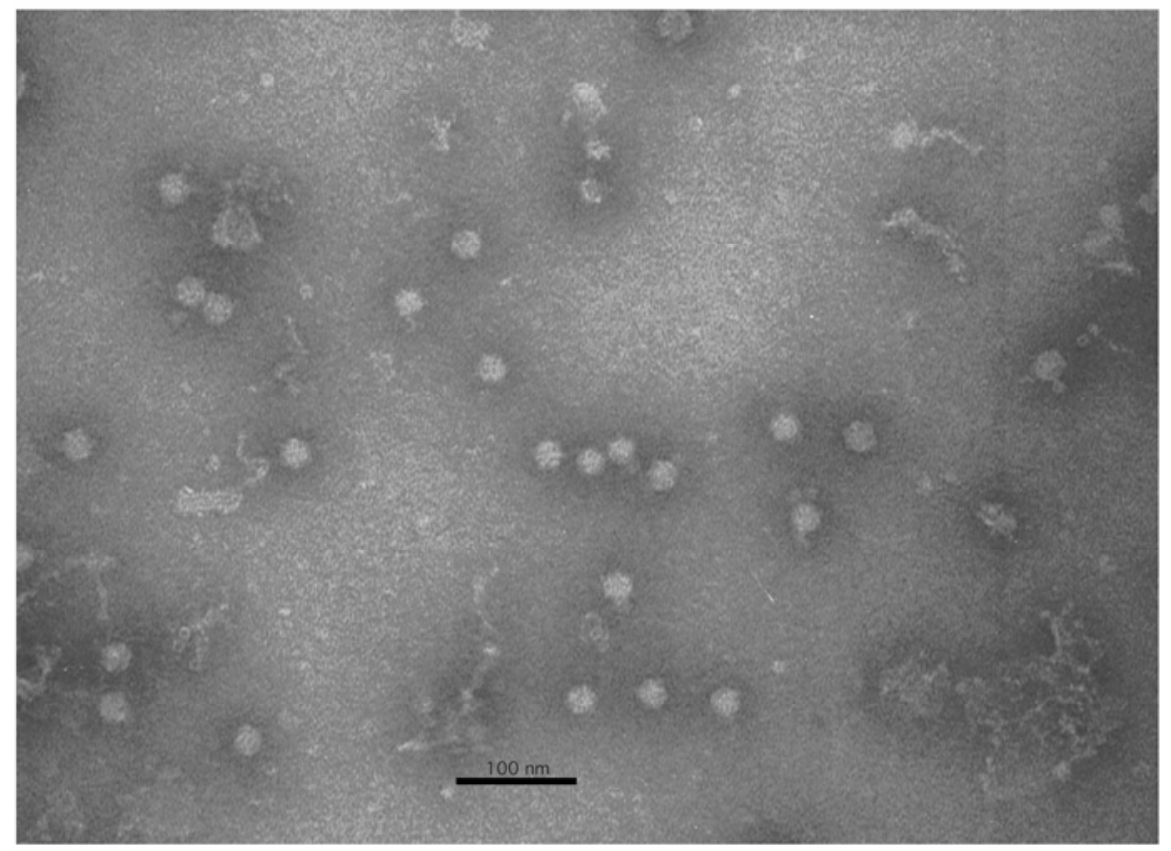

B

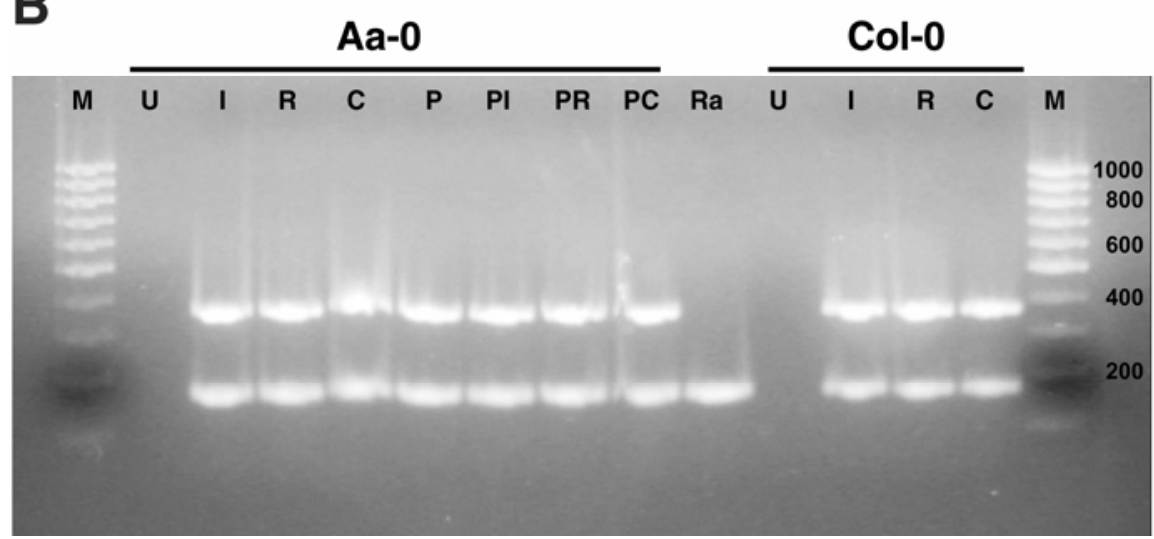

Fig. 2. Characteristics of Turnip ringspot virus (TuRSV). A, Transmission electron micrograph at $\times 100,000$ magnification of partially purified TuRSV negatively stained with phosphotungstic acid. Bar indicates $100 \mathrm{~nm}$. B, Reverse transcriptase-polymerase chain reaction (RT-PCR) analysis of TuRSV infection in Arabidopsis thaliana. Aa-0 and Col-0 plants (indicated) were inoculated with TuRSV, harvested at 16 days postinoculation, and separated into I, inoculated, $R$, noninoculated rosette, and C, noninoculated cauline, leaves. The appropriate leaves from 15 plants were pooled together and analyzed by RT-PCR using two primer sets in the same reaction. The TuRSV RNA1sp-1F and TuRSV RNA1sp-2R amplify a 369-bp fragment (nucleotides 705-1073) from TuRSV RNA 1 (upper band). The second pair, TuRSV RNA2sp-1F and TuRSV RNA2sp-2R, amplify a 168-bp fragment (nucleotides 23-190) from TuRSV RNA 2 (lower band). P, partially purified TuRSV; PI, inoculated leaves from plant inoculated with partially purified virus; PR, noninoculated rosette leaves from plant inoculated with partially purified virus; PC, noninoculated cauline leaves from plant inoculated with partially purified virus. M, 100-bp markers (Fisher Scientific), sizes indicated on right; Ra, Radish mosaic virus (American Type Culture Collection PV 138) dried tissue extracted and then amplified with the same double primer set as above. 
thaliana to TuRSV, several ecotypes were inoculated. TuRSV symptoms varied considerably among the 23 ecotypes tested, with 12 ecotypes developing systemic symptoms (Table 1). By 8 DPI, A. thaliana ecotypes Nw-4 and Ct-1 exhibited chlorotic

lesions on inoculated leaves, while Aa-0 showed chlorotic lesions with necrotic centers. None of the other ecotypes showed symptoms on inoculated leaves.

As the infection progressed, symptoms were observed on noninoculated rosette

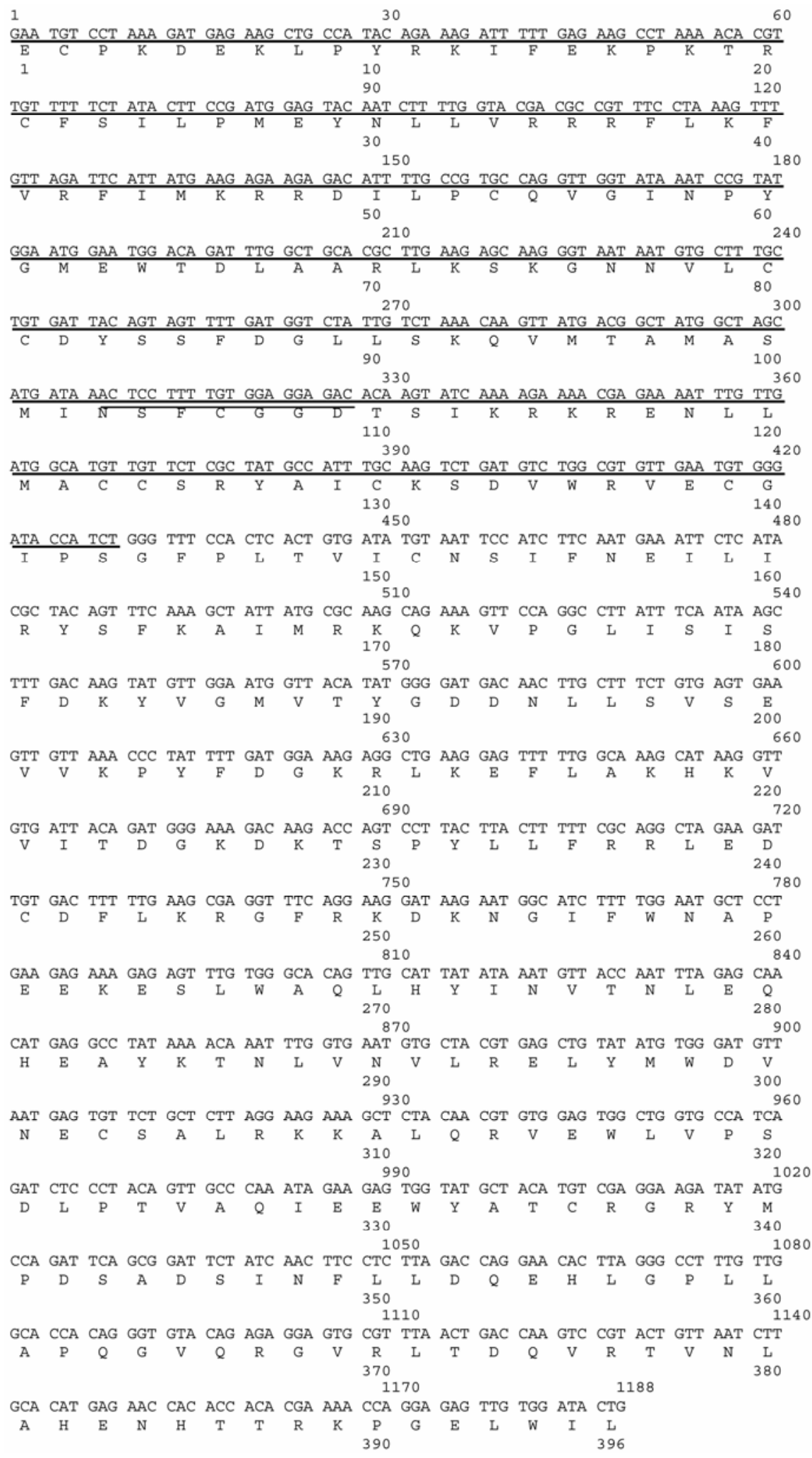

Fig. 3. Nucleotide and predicted protein sequence of a portion of Turnip ringspot virus (TuRSV) RNA 1. Numbers indicate nucleotide (above nucleotide sequence) and amino acid (below amino acid sequence) positions. Underlined, sequence of the initial 429-bp reverse transcriptase-polymerase chain reaction (RT-PCR) product (nucleotides 1-429); double underline, TuRSV-1F primer. and cauline leaves for many ecotypes. Infected $\mathrm{Aa}-0$, Nd-0, and Nw-4 ecotypes showed chlorotic lesions on noninoculated rosette leaves that eventually became necrotic beginning about 10 DPI (Fig. 6). By 18 DPI, chlorotic lesions were observed on noninoculated rosette and cauline leaves of ecotypes Be- $0, \mathrm{Ct}-1$, Di-0, Est-0, Oy-0, Pla-1, Rsch-4, Sv-0, and Tsu- 0 . In addition to these symptoms, Est-0 showed vein clearing on cauline leaves. Finally, ecotypes Alu-1, Bur-0, Col-0, Fr-2, Kas-1, Le-0, Mh-0, Np-1, No-0, RLD, Wil-2, and Ws-0 did not develop symptoms during the course of these experiments.

Ct-1 was the only ecotype that died after virus inoculation, and this occurred by about 30 DPI. All of the other ecotypes showing symptoms eventually recovered from the infection and set seed by 84 DPI. TuRSV-infected Aa-0 (Fig. 6) and Nw-4 plants showed an interesting symptom progression. For example, the majority of rosette leaves of infected Aa- 0 plants were dead by about 18 DPI. However, lateral meristems were not killed by the virus, and the plants started to recover from the infection, developing new rosettes by about 16 DPI. By 21 DPI, the plants had developed good rosettes, but were also beginning to show another round of viral symptoms on the recovered tissue. However, after this time, the plants recovered a second time, flowered, and set seed by $84 \mathrm{DPI}$.

Col-0 plants defective in the ethylene, jasmonic acid, and salicylic acid signaling pathways are asymptomatic when inoculated with TuRSV. Col-0 ecotype plants did not show symptoms when in oculated with TuRSV (Fig. 6A). To determine if the Col-0 plants were infected by the virus but asymptomatic, TuRSVinoculated Col- 0 and Aa- 0 plants were harvested at 14 DPI, and cell sap derived from this tissue was inoculated to Aa- 0 indicator plants. Aa-0 plants inoculated with cell sap from TuRSV-inoculated Col0 plants remained asymptomatic, while indicator plants inoculated with cell sap from infected Aa- 0 plants were highly symptomatic by 14 DPI. Interestingly, both TuRSV RNAs could be detected by RTPCR in all portions of Col-0 plants tested (Fig. 2B).

Defense pathways in A. thaliana often appear to operate via the salicylic acid, ethylene, or jasmonic acid signaling molecules $(12,36)$. Therefore, Col-0 plants harboring mutations in these signaling pathways were predicted to show increased susceptibility to TuRSV. For the salicylic acid pathway, pad4, a mutant that is impaired in the accumulation, and nprl, a mutant that is insensitive to this signaling molecule $(8,37)$, were tested. For the ethylene pathway, the ein 2 and etrl mutants, which are impaired in their responses to this hormone (15), were examined. Finally, 
the jarl mutant that is impaired in its jasmonic acid responses (30) was studied. While Aa-0 control plants inoculated with TuRSV showed typical symptoms, all of the Col-0 mutants were asymptomatic. Cell sap derived from harvested pooled tissue from TuRSV-infected wild-type or mutant Col-0 plants, subsequently inoculated onto Aa- 0 , induced no obvious symptoms.

\section{DISCUSSION}

Based on a survey of the Virus Identification Database Exchange $(5,6,9,10)$, few viruses infecting turnip show ring spot symptoms. Therefore, when a virus inducing ring spot symptoms on turnips was discovered, further characterization of the pathogen was performed. Electron microscopy of enriched virus preparations showed icosahedral particles approxi- mately $28 \mathrm{~nm}$ in diameter. This virus was provisionally termed Turnip ringspot virus (TuRSV). RT-PCR testing suggested that TuRSV was a comovirus. This was confirmed when the sequences were determined for segments of RNA 1 and RNA 2. Both the RNA 1 and RNA 2 RT-PCR products were most similar to members of the genus Comovirus based on BLAST analyses.

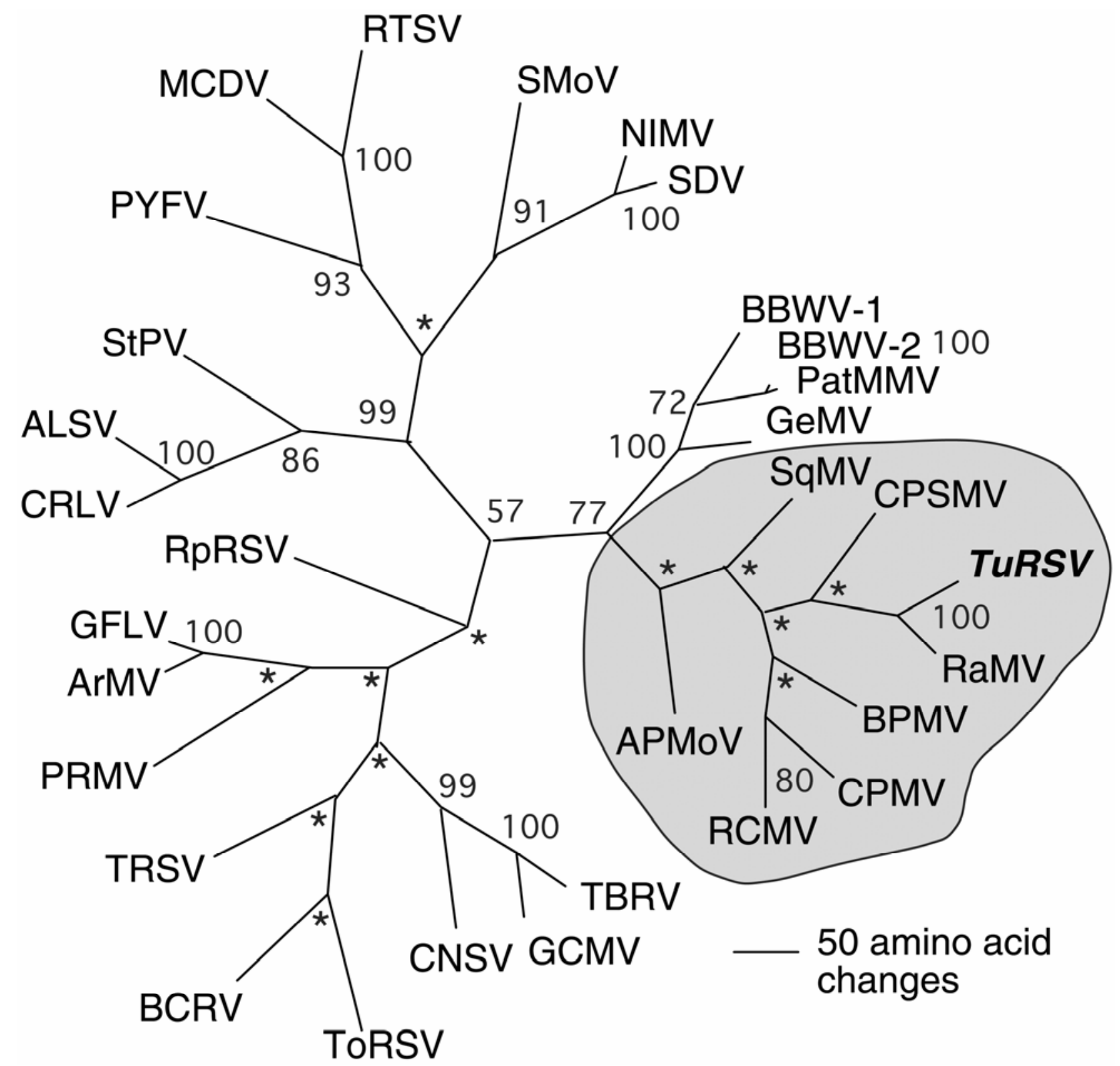

Fig. 4. Unrooted phylogenetic tree indicating relationship of the predicted Turnip ringspot virus (TuRSV) RNA 1 polypeptide segment to the aligned region of other plant viruses. Length of branches corresponds to number of amino acid differences as indicated by the scale bar; numbers at nodes indicate percent bootstrap scores; asterisks denote bootstrap values below 50\%. Shaded region indicates comoviruses; bold italics indicates TuRSV. Virus abbreviations and accessions (in parentheses below) are: ALSV (NP_620568), Apple latent spherical virus; APMoV (Q02941), Andean potato mottle virus; ArMV (AAQ73821), Arabis mosaic virus; AYRSV (CAJ33468), Artichoke yellow ringspot virus; BBWV-1 (NP_945134), Broad bean wilt virus 1; BBWV-2 (AAD38152), Broad bean wilt virus 2; BRAV (NP_612604), Blackcurrent reversion virus; BPMV (AAM73715), Bean pod mottle virus; CLRV (CAE83562), Cherry leafroll virus; CNSV (NP_734017), Cycas necrotic stunt virus; CPMV (NP_613283), Cowpea mosaic virus; CPSMV (NP_619518), Cowpea severe mosaic virus; CRLV (AAW92113), Cherry rasp leaf virus; GCMV (CAA33405), Grapevine chrome mosaic virus; GeMV (BAD99001), Gentian mosaic virus; GFLV (NP_619689), Grapevine fanleaf virus; MCDV (AAV86083), Maize chlorotic dwarf virus; NIMV(BAA74537), Naval orange infectious mottling virus; PBRV (CAE83563), Potato black ringspot virus; PatMMV (NP_647592), Patchouli mild mosaic virus; PRMV (AAB69867), Peach rosette mosaic virus; PYFV (NP_619734), Parsnip yellow fleck virus; RaMV (AAY32935), Radish mosaic virus; RCMV (NP_734030), Red clover mottle virus; RpRSV (AAQ77238), Raspberry ringspot virus; RTSV (NP_042507), Rice tungro spherical virus; SDV (NP_620566), Satsuma dwarf virus; SLRSV (YP_227376), Strawberry latent ringspot virus; SMoV (NP_599086), Strawberry mottle virus; StPV (AAZ76594), Stocky prune virus; SqMV (NP_620657), Squash mosaic virus; TBRV (AAN72830), Tomato black ring virus; ToRSV (NP_620765), Tomato ringspot virus; TRSV (NP_919040), Tobacco ringspot virus; TuRSV (DQ665367), Turnip ringspot virus. 
The conserved domain database scan (24) performed while the BLAST search was being conducted indicated that amino acids 1-335 of the TuRSV RNA 1-derived RT-PCR product were analogous to an RNA-dependent RNA-polymerase domain (pfam00680). In the comoviruses, this polymerase is approximately $84 \mathrm{kDa}$ in size and is located at the C-terminus of the RNA 1-derived polyprotein. This sequence contains the GDD sequence that plays a role in catalyzing the polymerase reaction (17).

Phylogenetic analysis based on the sequence of a portion of the $84-\mathrm{kDa}$ polymerase polypeptide sequence encoded by RNA 1 indicates that the comoviruses cluster together into one major clade that includes TuRSV. TuRSV is most similar to $\mathrm{RaMV}$, and the two viruses form their own

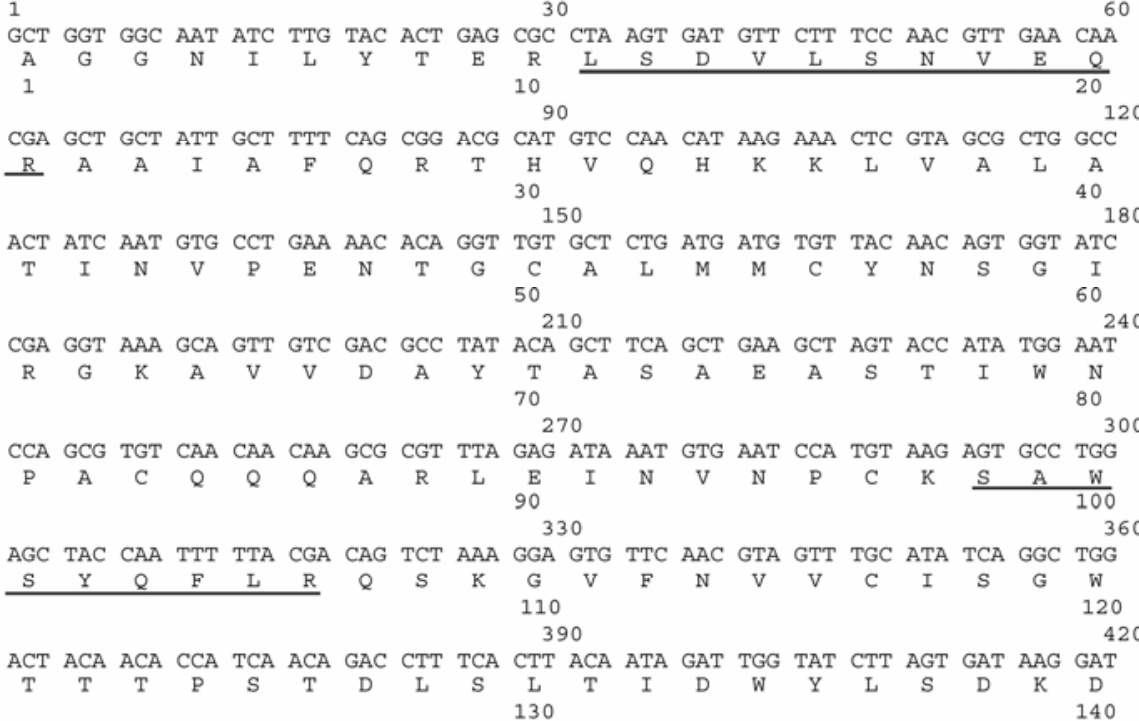

Fig. 5. Nucleotide and predicted protein sequence of a portion of Turnip ringspot virus (TuRSV) RNA 2. Numbers indicate nucleotide (above nucleotide sequence) and amino acid (below amino acid sequence) positions. Underlined amino acids correspond to peptides derived from the 40-kDa protein identified by sodium dodecyl sulfate-polyacrylamide gel electrophoresis (SDS-PAGE) of purified virus preparations.

Table 1. Turnip ringspot virus symptoms on Arabidopsis ecotypes

\begin{tabular}{|c|c|c|c|c|}
\hline Ecotype & $\begin{array}{c}\text { Inoculated } \\
\text { leaves }^{\mathbf{a}}\end{array}$ & $\begin{array}{c}\text { Systemic } \\
\text { leaves }^{b}\end{array}$ & $\begin{array}{c}\text { Final } \\
\text { result }^{c}\end{array}$ & $\begin{array}{c}\text { Development } \\
\text { rate }^{\mathrm{d}}\end{array}$ \\
\hline $\mathrm{Aa}-0$ & CL/NL & CL/VC & $\mathrm{I} / \mathrm{R} / \mathrm{I} / \mathrm{R}$ & $\mathrm{S}$ \\
\hline Alu-0 & & & NS & $\mathrm{F}$ \\
\hline $\mathrm{Be}-0$ & & CL & $\mathrm{I} / \mathrm{R}$ & $\mathrm{S}$ \\
\hline Bur-0 & & & NS & $\mathrm{F}$ \\
\hline Col-0 & & & NS & M \\
\hline $\mathrm{Ct}-1$ & CL & CL/VC & $\mathrm{I} / \mathrm{D}$ & M \\
\hline Di-0 & & CL & $\mathrm{I} / \mathrm{R}$ & $\mathrm{F}$ \\
\hline Fr-2 & & & NS & $\mathrm{S}$ \\
\hline Est-0 & & CL/VC & $\mathrm{I} / \mathrm{R}$ & M \\
\hline Kas-1 & & & NS & M \\
\hline Le-0 & & & NS & $\mathrm{F}$ \\
\hline Mh-0 & & & NS & S \\
\hline $\mathrm{Nd}-0$ & & $\mathrm{CL}$ & $\mathrm{I} / \mathrm{R}$ & $\mathrm{F}$ \\
\hline No-0 & & & NS & M \\
\hline Np-1 & & & NS & $\mathrm{F}$ \\
\hline Nw-4 & CL & CL/VC & $\mathrm{I} / \mathrm{R} / \mathrm{I} / \mathrm{R}$ & M \\
\hline Oy-0 & & CL/VC & $\mathrm{I} / \mathrm{R}$ & M \\
\hline Pla-1 & & CL & $\mathrm{I} / \mathrm{R}$ & $\mathrm{S}$ \\
\hline RLD & & & NS & M \\
\hline Rsch-4 & & $\mathrm{CL}$ & $\mathrm{I} / \mathrm{R}$ & $\mathrm{S}$ \\
\hline Sv-0 & & $\mathrm{CL}$ & $\mathrm{I} / \mathrm{R}$ & $\mathrm{S}$ \\
\hline Tsu-0 & & $\mathrm{CL}$ & $\mathrm{I} / \mathrm{R}$ & $\mathrm{S}$ \\
\hline Wil-2 & & & NS & $\mathrm{F}$ \\
\hline Ws-0 & & & NS & $\mathrm{F}$ \\
\hline
\end{tabular}

a Symptoms on inoculated leaves: CL, chlorotic lesions; NL, necrotic lesions.

b Symptoms on systemic leaves: CL, chlorotic lesions; VC, vein clearing.

c Progression of infection: I, infection; R, recovery; D, death; NS, no symptoms.

${ }^{\mathrm{d}}$ Developmental rate based on time to bolting following germination: F, fast (bolts 15.5 to 18 days postgermination); M, moderate (bolts 19 to 31 days postgermination); and S, slow (bolts 32 to 41 days postgermination) (22). subclade within the comoviruses. This is interesting since both viruses are capable of infecting plants within the Brassicaceae causing ring spot symptoms (see $5,6,9,10,29$ for data regarding RaMV). The TuRSV polypeptide is less than $80 \%$ identical at the amino acid sequence level to the orthologous RaMV protein segment. This degree of sequence identity indicates that the TuRSV sequence is different from that of RaMV. Likewise, RT-PCR reactions employing TuRSV RNA 1 primers failed to generate a product from a RaMV template. Taken together, these data indicate that TuRSV is distinct from RaMV.

The portion of RNA 2 sequence reported here (Fig. 5) encoded a deduced polypeptide orthologous to the N-terminalproximal segment of the CPMV large capsid protein (amino acids 496-635; GenBank accession no. CAA25314). The phylogenetic tree for the TuRSV RNA 2 sequence was much smaller than that for RNA 1 because it showed limited amino acid sequence identity (35 to 47\%) with only the comoviruses (data not shown). These data confirm that TuRSV is a distinct member of the genus Comovirus.

SDS-PAGE performed on infected plant tissue extracts was not sensitive enough to detect viral polypeptides (data not shown). In addition, virus particles were detected by electron microscopy only after partial purification. Taken together, these data suggest that TuRSV accumulated to a relatively low titer in infected plants. Interestingly, when virus was partially purified, several ribosomal proteins were found along with the virus capsid protein. The size of the TuRSV coat protein $(\sim 40 \mathrm{kDa})$ is in the correct range for a comovirus $(14,16)$. However, comoviruses typically encode two coat proteins: a large one about $40 \mathrm{kDa}$ and a smaller one about $20 \mathrm{kDa}$. No 20-kDa protein band was observed on the gels of enriched virus fractions. This suggests at least three possibilities. First, the TuRSV genome may not encode an $\sim 20-\mathrm{kDa}$ protein. Second, the TuRSV "small" coat protein may be the same size as the larger one and might co-migrate on the gel. Third, the $\sim 20-\mathrm{kDa}$ protein is there but below the detection limit by SDSPAGE.

TuRSV was mechanically transmissible to another member of the Brassicaceae. Examination of TuRSV infection in $A$. thaliana indicated that ecotypes vary considerably in their responses to the pathogen. In fact, these data suggest that $A$. thaliana ecotypes exhibit at least four types of responses to TuRSV. First, the Ct1 ecotype is killed by TuRSV. Second, Aa0 and Nw-4 go through two rounds of symptom display and recovery. Third, most of the ecotypes initially showing symptoms (e.g., Est-0) recover from the infection. Finally, many of the ecotypes tested, including Col-0, did not show symptoms when inoculated with TuRSV. 
Perhaps the most interesting ecotypes were those such as Est-0 and Aa-0, which pass through one and two rounds of symptom display and recovery, respectively. This type of host-virus system is unique to our experience with A. thaliana. However, the two rounds of symptom display and recovery exhibited by the Aa- 0 and Nw-4 ecotypes are reminiscent of the situation with the Comovirus sp. Bean pod mottle virus (BPMV) in soybean (13). Because recovery of plants is often associated with RNA interference (RNAi) (33-36), this may provide an explanation for the phenomena observed with TuRSV infection of these A. thaliana ecotypes. These data are intriguing because at least one comovirus protein/gene has been proposed to suppress RNAi in the host (7). Because most of the ecotypes showing symptoms when inoculated with TuRSV recover from infection, these data would suggest that TuRSV cannot completely suppress RNAi. Possibly repression of RNAi is a characteristic either that TuRSV has lost, or that is not effective in certain $A$. thaliana ecotypes.

As observed previously with other viruses (20-22), ecotypes that flower rapidly appear more resistant to TuRSV than plants that flower more slowly. Some of this is likely due to "developmental resistance (22)." Developmental resistance was proposed to be due to the pattern of virus transport through the plant and could explain why most of the rapidly flowering ecotypes (e.g., Alu-1, Bur-0, Le- 0 , Np-1, Wil-2, and Ws-0) are asymptomatic when inoculated with TuRSV. In contrast, the majority of the slow-flowering ecotypes (e.g., Aa-0, Be-0, Pla-1, Rsch-4, Sv-0, and Tsu-0) show symptoms when infected by TuRSV, even though they eventually recover. This is, of course, not an absolute rule, because there are fast-flowering ecotypes (e.g., Di-0 and Nd-0) that show symptoms when inoculated with TuRSV, and there are asymptomatic slowflowering varieties (e.g., Fr-2 and Mh-0). The ecotypes that flower at a moderate rate are more variable, containing an equal number of symptomatic (e.g., Ct-1, Est-0, $\mathrm{Nw}-4$, and $\mathrm{Oy}-0$ ) and asymptomatic (e.g., Col-0, Kas-1, No-0, and RLD) plants when inoculated with TuRSV.

As appears to be true of other plant viruses, the symptoms induced by TuRSV on $A$. thaliana ecotypes are virus-specific. For example, both Di- 0 and Tsu- 0 are susceptible to TuRSV, but resistant to Turnip crinkle virus and to most isolates of Cauliflower mosaic virus (CaMV), respectively $(1,4,11,21,25,28)$. The Aa-0 ecotype is susceptible to both CaMV and Beet curly top virus, but recovery of the plants after infection in either case was not reported $(19,20)$. A similar observation is true for Est-0 plants: they are susceptible to CaMV and Cucumber mosaic virus but recovery was not observed
$(20,32)$. Est-0 is infected with lethal results by another member of the Comoviridae, Tobacco ringspot virus (TRSV) (18). Hence, different members of a virus family can induce different symptoms on the same ecotype.

Finally, Col-0 is tolerant to TuRSV infection because the plants were asymptomatic, yet virus could still be detected throughout the plant (16). This is intriguing because Col-0 is also tolerant of TRSV infection (18). Impairment of the ethylene, jasmonic acid, or salicylic acid signaling pathways in Col-0 did not compromise the response of these plants to TuRSV. Hence, the ethylene, jasmonic acid, or salicylic acid signaling pathways are not required to inhibit symptom formation; otherwise these plants would be symptomatic. Alternatively, these signal- ing pathways may be functionally redundant.

It is intriguing that infectious virus was not recovered from TuRSV-infected $A$. thaliana. Our prior data show that TuRSV accumulated to low titers in infected plants. Perhaps TuRSV accumulated to lower levels in Col-0 than in the other ecotypes. Under these circumstances, TuRSV could be detected by RT-PCR but may not be present at a high enough quantity to initiate new infections when inoculated to indicator plants.

In summary, we report the characterization of a comovirus discovered in Ohio, provisionally named TuRSV, that infects plants in the Brassicaceae. TuRSV infects A. thaliana ecotypes with a range of consequences. Thus, we can now employ the power of A. thaliana molecular genetics to study Comovirus-host relations.
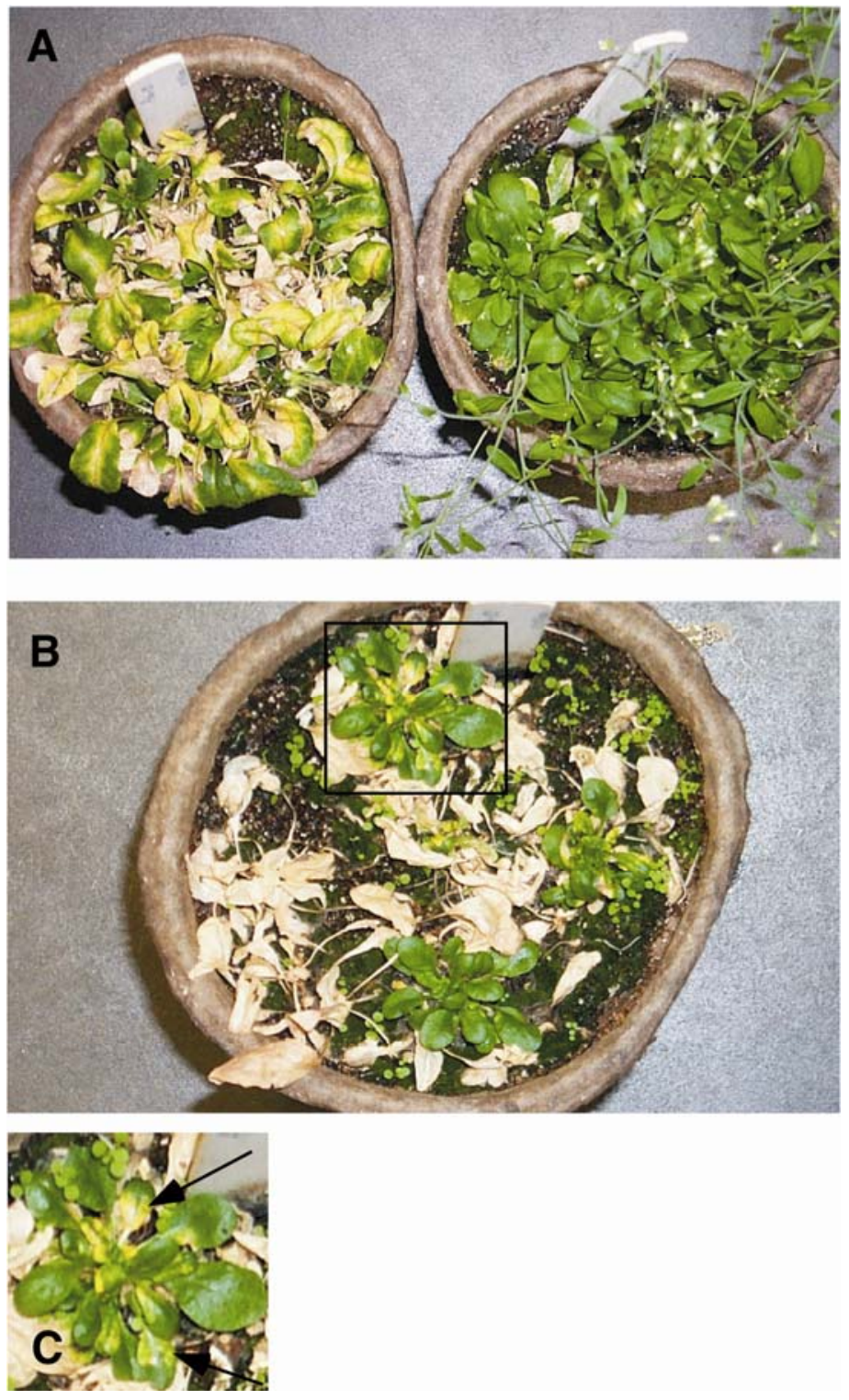

Fig. 6. Responses of Arabidopsis thaliana ecotypes to Turnip ringspot virus (TuRSV). A, Aa-0 (left) and Col-0 (right) infected with TuRSV and photographed at 14 days postinoculation. B, Recovery and development of systemic symptoms on Aa- 0 plants by TuRSV. Aa- 0 plants at 21 days postinoculation show the development of new (recovered) rosette leaves and are surrounded by a halo of dead leaves. C, Enlargement of boxed area of B showing reinfection by TuRSV. Arrow indicates a second round of infection on recovered tissue. 


\section{ACKNOWLEDGMENTS}

We thank John Gray, Stephen Goldman, Lirim Shemshedini (The University of Toledo, Toledo, $\mathrm{OH})$, and the University of Toledo Plant Science Research Center for their assistance. We also thank Stephen H. Howell (Iowa State University, Ames) for the Arabidopsis ecotypes and The Arabidopsis Biological Resource Center at the Ohio State University (Columbus) for the mutants used in this study. Finally, we thank Agdia (Elkhardt, IN) for their kind assistance in providing the TuRSV RT-PCR product. This work was supported in part by NIH grant no. 1R15AI5064101, USDA grant no. 96-3503-3284, USDA SCA 58-3607-1-193, and the University of Toledo deARCE Memorial Endowment Fund in Support of Medical Research and Development, and the Ohio Plant Biotechnology Consortium, administered through the Ohio Agricultural Research and Development Center.

\section{LITERATURE CITED}

1. Agama, K., Beach, S., Schoelz, J., and Leisner, S. M. 2002. The 5' third of Cauliflower mosaic virus gene VI conditions resistance breakage in Arabidopsis ecotype Tsu-0. Phytopathology 92:190-196.

2. Altschul, S. F., Madden, T. L., Schaffer, A. A., Zhang, J., Zhang, Z., Miller, W., and Lipman, D. J. 1997. Gapped BLAST and PSI-BLAST: A new generation of protein database search programs. Nucleic Acids Res. 25:3389-3402.

3. Ausubel, F. M., Brent, R., Kingston, R. E., Moore, D. D., Seidman, J. G., Smith, J. A., and Struhl, K. 1993. Current Protocols in Molecular Biology. Greene Publishing Associates and John Wiley \& Sons, Cambridge, MA.

4. Balazs, E., and Lebeurier, G. 1981. Arabidopsis is a host of Cauliflower mosaic virus. Arabidopsis Inf. Serv. 18:130-134.

5. Boswell, K. F., Dallwitz, M. J., Gibbs, A. J., and Watson, L. 1986. The VIDE (Virus Identification Data Exchange) project: A database for plant viruses. Rev. Plant Pathol. 65:221231

6. Brunt, A. A., Crabtree, K., Dallwitz, M. J., Gibbs, A. J., Watson, L., and Zurcher, E. J. Plant Viruses Online: Descriptions and Lists from the VIDE Database (20) August, 1996. http://image.fs.uidaho.edu.vide/

7. Canizares, M. C., Taylor, K. M., and Lomonossoff, G. P. 2004. Surface-exposed Cterminal amino acids of the small coat protein of Cowpea mosaic virus are required for suppression of silencing. J. Gen. Virol. 85:34313435.

8. Cao, H., Bowling, S. A., Gordon, A. S., and Dong, X. 1994. Characterization of an Arabidopsis mutant that is nonresponsive to inducers of systemic acquired resistance. Plant Cell 6:1583-1592.

9. Dallwitz, M. J. 1980. A general system for coding taxonomic descriptions. Taxon 29:4147.

10. Dallwitz, M. J., Paine, T. A., and Zurcher, E. J.
1993. User's Guide to the DELTA System: A general system for processing taxonomic descriptions. 4th ed. CSIRO Division of Entomology, Canberra.

11. Dempsey, D. A., Wobbe, K. K., and Klessig, D. F. 1993. Resistance and susceptible responses of Arabidopsis thaliana to Turnip crinkle virus. Phytopathology 83:1021-1029.

12. Feys, B. J., and Parker, J. E. 2000. Interplay of signaling pathways in plant disease resistance. Trends Genet. 16:449-455.

13. Gillaspie, A. G., and Bancroft, J. B. 1965. The rate of accumulation, specific infectivity, and electrophoretic characteristics of Bean pod mottle virus in bean and soybean. Phytopathology 55:906-908.

14. Goldbach, R. W., and Wellink, J. 1996. Comoviruses: Molecular biology and replication. Chapter 3 in: The Plant Viruses: Polyhedral Virions and Bipartite Rna Genomes. B. D. Harrison and A. F. Murant, eds. Plenum Press, New York.

15. Guzman, P., and Ecker, J. R. 1990. Exploiting the triple response of Arabidopsis to identify ethylene-related mutants. Plant Cell 2:513523.

16. Heitefuss, R. 1997. General principles of hostparasite interactions. Pages 19-32 in: Resistance of Crop Plants Against Fungi, $H$. Hartleb, R Heitefuss, and H.-H. Hoppe, eds. Gustav Fischer, Stuttgart.

17. Hull, R. 2002. Matthews' Plant Virology. 4th ed. Academic Press, San Diego.

18. Lee, J. M., Hartman, G. L., Domier, L. L., and Bent, A. F. 1996. Identification and map location of TTR1, a single locus in Arabidopsis thaliana that confers tolerance to Tobacco ringspot nepovirus. Mol. Plant-Microbe Interact. 9:729-735.

19. Lee, S., Stenger, D. C., Bisaro, D. M., and Davis, K. R. 1994. Identification of loci in Arabidopsis that confer resistance to geminivirus infection. Plant J. 6:525-535.

20. Leisner, S. M., and Howell S. H. 1992. Symptom variation in different Arabidopsis thaliana ecotypes produced by Cauliflower mosaic virus. Phytopathology 82:1042-1046.

21. Leisner, S. M., Turgeon, R., and Howell, S. H. 1992. Long distance movement of Cauliflower mosaic virus in infected turnip plants. Mol. Plant-Microbe Interact. 5:41-47.

22. Leisner, S. M., Turgeon, R., and Howell, S. H. 1993. Effects of host plant development and genetic determinants on the long-distance movement of Cauliflower mosaic virus in Arabidopsis. Plant Cell 5:191-202.

23. Lomonossoff, G. P., and Shanks, M. 1983. The nucleotide sequence of cowpea mosaic virus B RNA. EMBO J. 2:2253-2258.

24. Marchler-Bauer, A., Anderson, J. B., Cherukuri, P. F., DeWeese-Scott, C., Geer, L. Y., Gwadz, M., He, S., Hurwitz, D. I., Jackson, J. D., Ke, Z., Lanczycki, C. J., Liebert, C. A., Liu, C., Marchler, G. H., Mullokandov, M., Shoemaker, B. A., Simonyan, V., Song, J. S.,
Thiessen, P. A., Yamashita, R. A., Yin, J. J Shang, D., and Bryant, S. H. 2005. CDD: A conserved domain database for protein classification. Nucleic Acids Res. 33:D192-196.

25. Melcher, U. 1989. Symptoms of Cauliflower mosaic virus infection in Arabidopsis thaliana and turnip. Bot. Gaz. 150:139-147.

26. Petrzik, K., Hola, M., and Spak, J. 2005. Complete nucleotide sequence of Radish mosaic virus RNA polymerase gene and phylogenetic relationships in the genus Comovirus. Acta Virol. 49:271-275.

27. Redinbaugh, M. G., Seifers, D. L., Meulia, T., Abt, J. J., Anderson, R. J., Styer, W. E., Ackerman, J., Salomon, R., Houghton, W. Creamer, R., Gordon, D. T., and Hogenhout, S. A. 2002. Maize fine streak virus, a new leafhopper-transmitted rhabdovirus. Phytopathology 92:1167-1174.

28. Simon, A. E., Li, X. H., Lew, J. E., Stange, R., Zhang, C., Polacco, M., and Carpenter, C. D. 1992. Susceptibility and resistance of Arabidopsis thaliana to Turnip crinkle virus. Mol. Plant-Microbe Interact. 5:496-503.

29. Spak, J. 1992. Characterization, purification and serology of the Czechoslovak isolate of Radish mosaic virus. Acta Virol. 36:191-197.

30. Staswick, P. E., Su, W., and Howell, S. H 1992. Methyl jasmonate inhibition of root growth and induction of a leaf protein are decreased in an Arabidopsis thaliana mutant. Proc. Natl. Acad. Sci. USA 89:6837-6840.

31. Swofford, D. L. 2000. PAUP*: Phylogenetic Analysis Using Parsimony and Other Methods (software). Sinauer Associates, Sunderland, MA.

32. Takahashi, H., Goto, N., and Ehara, Y. 1994. Hypersensitive response in Cucumber mosaic virus-inoculated Arabidopsis thaliana. Plant $\mathrm{J}$ 6:369-377.

33. van Regenmortel, M. H. V., Fauquet, C. M., Bishop, D. H. L., Carstens, E. B., Estes, M. K., Lemon, S. M., Maniloff, J., Mayo, M. A. McGeoch, D. J., Pringle, C. R., and Wickner, R. B. 2000. Virus Taxonomy: Seventh Report of the International Committee on Taxonomy of Viruses. Academic Press, San Diego.

34. Voinnet, O. 2001. RNA silencing as a plant immune system against viruses. Trends Genet. 17:449-459.

35. Voinnet, O., Pinto, Y. M., and Baulcombe, D. C. 1999. Suppression of gene silencing: A general strategy used by diverse DNA and RNA viruses of plants. Proc. Natl. Acad. Sci. USA 96:14147-14152.

36. Whitham, S. A., and Dinesh-Kumar, S. P 2002. Signalling in plant-virus interactions. In: Plant Signal Transduction. D. Scheel and C. Wasternack, eds. Oxford University Press, Oxford.

37. Zhou, N., Tootle, T. L., Tsui, F., Klessig, D. F., and Glazebrook, J. 1998. PAD4 functions upstream from salicylic acid to control defense responses in Arabidopsis. Plant Cell 10:10211030 